\title{
Assessment of Soil Fertility Management Practices under Small Holder Systems in Kafin Madaki Area Bauchi State
}

\author{
Faruk Aliyu
}

A. M. Saddique

\section{A. Sulaiman}

\section{S.I. Abdullahi}

School of General Studies, Abubakar Tatari Ali Polytechnic Bauchi, Bauchi state, Nigeria

\author{
Doi:10.5901/mjss.2014.v5n26p107
}

\begin{abstract}
The study was carried out to assess the soil fertility management practices under small holder systems in Kafin Madaki area, Bauchi State, Nigeria. Farmlands managed under long fallow, medium fallow and combine fertilizer and household waste were carefully selected during reconnaissance survey. Topographic view shows that both of the farmlands are nearly level and well drained. The farmlands are used in the cultivation of maize, millet, beans, groundnut and beniseed during rainy season and grazing of ruminant animals during dry months. Each of the farmland was divided into 3 grids and within each, a total of 3 surface samples $(0-10 \mathrm{~cm}$ depth) were taken using stratified random sampling. The samples taken from a grid were thoroughly mixed to form a composite sample. A portion of the 9 composite samples were taken to laboratory for routine analysis. Mean difference and analysis of variance (ANOVA) were tested. The result shows that among all variables tested only TN and AP shows significant difference. However, the mean values of the positive variables (such as clay, $N, P, \mathrm{Ca}, \mathrm{Mg}, \mathrm{ECEC}$, and total bases) were both higher in magnitude in soil managed under combine fertilizer and household waste. Conversely, the mean magnitudes of the negative variables (such as sand, $\mathrm{Na}$, and exchangeable acidity) are higher in short and long fallow system while the optimum variable (such as $\mathrm{pH}$ ) is at its optimum in the former. Increase in TN, AP and other positive variables in combine fertilizer and household waste management system is an indication of increased in fertility quality, and it may be attributed to the type of inorganic fertilizer (NPK 20-15-15 and NPK 15-15-15) and the bulk of organic materials been applied. Therefore for sustained agricultural productivity and food security, management of soil fertility based on the combine application of fertilizer and household waste is recommended.
\end{abstract}

Keywords: soil fertility, fertility variables, fallow, management, Kafin Madaki

\section{Introduction}

One of the fundamentals of soil fertility management roots from the need to protect and enhance its performance for profitable production and for preservation of its quality for generation to come. Although every soil fertility management practice has positive and negative impacts on the fertility variables and the behavior of the soil, the adoption of a specific system depends widely upon the environment, social, economic and technological attainment of the farmer. Rapid increase in human population in Nigeria, accompanied by decrease in land per capita brings the need for increased agricultural production which can only be sustained when the nutrient removed from the field are adequately replaced (Yusuf, 1994). Therefore, for a soil to continue to yield a harvest of desirable quantity the soil quality have to be improved or maintained through employment of the appropriate management practice.

Small holder farming in northern Nigeria is characterized by small and fragmented plot using simple implements with little investment and depending largely on self and family labor (Yusuf, 1994). In Kafin Madaki the study area this system of farming is dominant and has been practiced for several decades ago. Management of soil fertility under this system was done traditionally using fallow, though recently it has undergoes gradual decline by giving way to a combine fertilizer and household waste application.

Therefore, in order to guide the choice of the farmers on the appropriate management system to adopt, then the knowledge of the relationships between the systems and the fertility levels is needed. In adequate understanding of this relationships will not only constrain the economy and food security of the peasant farmers, but will in addition pose the soil resource into a continuous degradation condition. It is based on this premise that this study was set to assess the soil 
fertility management practices under small holder system in Kafin Madaki area, Bauchi state, Nigeria.

\section{Study Area}

Kafin Madaki in Bauchi state north eastern Nigeria is located between latitude $10^{0} 31^{\prime}$ and $11^{0} 00^{\prime} \mathrm{N}$ and longitude 9030 , and $10^{\circ} 00^{\prime} \mathrm{E}$. The area is under tropical wet and dry climate, coded as Aw by Koppen (1912). Rainfall in the area is up to $1000 \mathrm{~mm}$ though varied slightly from year to year. The temperature is high throughout the year though slight decline occur around December and February due to the effect of hamattan winds. The natural vegetation of the area is sudan savanna type though significantly altered by human activities. The geology constitute of Precambrian basement complex which is made up of igneous, gneisses, and granites. The soil is alfisols (USDA soil survey staff, 1999). The profiles are deep to very deep, well to poorly drain red or brown course textured tropical lateritic soils. Two most important soil fertility management systems include fallowing and the combine fertilizer and household applications.

\section{Materials and Methods}

\subsection{Soil sampling}

Farmlands been managed through medium fallow, long fallow and combine fertilizer and household waste were identified during reconnaissance survey. Permission for sampling was obtained from the farm owners. Careful observations of the nature of the slope and drainage condition were done. Surface samples (depth $=0-10 \mathrm{~cm}$ ) were taken from the chosen farmlands by dividing each into three (3) grids. Within each of these grids, three sampling sites were chosen randomly. The samples taken from a grid was thoroughly mixed to form a composite sample out of which a portion was taken to laboratory for routine analysis.

\subsection{Laboratory analysis}

Laboratory analysis of the soil fertility indicators such as total nitrogen (TN), available phosphorus (AP), soil organic matter (SOM), soil pH, potassium (K), calcium (Ca), magnesium (Mg), sodium ( $\mathrm{Na})$, exchangeable acidity and texture was conducted.

SOM and TN were determined using hydrometer (Gee and Bauder, 1986) and the semi-micro Kjeldahl method (Bremmer and Mulvaney, 1982), respectively. AP was determined using Burruel and Hernanado (Diez, 1982). Ca and Mg were determined by atomic absorption spectrometry while $\mathrm{K}$ and $\mathrm{Na}$ were determined by flame photometric method. The exchangeable acidity was performed by percolating soil with $1 \mathrm{~N} \mathrm{Kcl}$ solution. Titration was conducted using $0.025 \mathrm{NaOH}$ with the percolate to determine the acidity. Soil ph was determined using 1:2.5 suspension in $\mathrm{H}_{2} \mathrm{O}$ and $\mathrm{Cacl}_{2}$ while particle size analysis was made using hydrometer method described by Gee and Bauder (1986).

\subsection{Data presentation and analysis}

Data generated from laboratory analysis of the collected samples were organized in tables. Mean values were computed and analysis of variance (ANOVA) was tested to describe the relationships between and within the soil properties.

\section{Results and Discussion}

The $\mathrm{pH}$ values of the soils show no significant difference. However, the mean value of the variable (table 2) in combine fertilizer and household waste management, medium and long fallow were 7.0, 6.1 and 6.1 respectively. This is an indication that the soil reaction has been affected by the management practices in place. Yusuf (2000) observed that the increase or decrease of $\mathrm{pH}$ readings to neutral levels signifies increase in fertility quality

The result also shows that, there is no significant difference in organic matter content among soils under different management system, but, the mean values of the property as presented in table 2 shows a slight decrease in magnitude from long fallow to medium fallow and to the combine fertilizer and household management. High content of the OM in long fallow soil may be resulted from the long time capital accumulation of the material from the growing vegetation during the resting period. It has been observed that, the length of the fallow period has a direct relationship with capital accumulation of the organic material (Faruk, 2010).

On another hand, the total nitrogen contents show significant difference among the soils. The mean value of about 
$0.072 \%$ were recorded in soil managed

Under combine fertilizer and household system while an equal amount of $0.035 \%$ each were recorded in medium and long fallow managements respectively. Increased magnitude in TN in the combine fertilizer and household managed soils may be attributed to the large volume of organic materials regularly been supplied to the farm during dry season majority of which includes animal dug and vegetal materials. Lower content in the long and medium fallow may not be unconnected to high removal of the property through rampant grazing and perennial bush burning in the area. TN is one of the positive properties whose increase signifies increase in fertility quality (Yusuf, 2000)

Similarly, the values of the available phosphorus also show significant difference. The mean values of $20.12 \mathrm{ppm}$ were recorded in soil managed under combine fertilizer and household waste while 7.3ppm and 9.3ppm were recorded in soil managed under medium and long fallow respectively. This wider variation may be attributed to the effects of fertilizer (NPK 20-10-10 and NPK 15-15-15) applied during recent farming and which contain phosphorus element therein. Similar observation was made by Olowolafe(2008). Increase in AP is an indication of increase in fertility quality (Yusuf, 2000)

Table 1: fertility variables

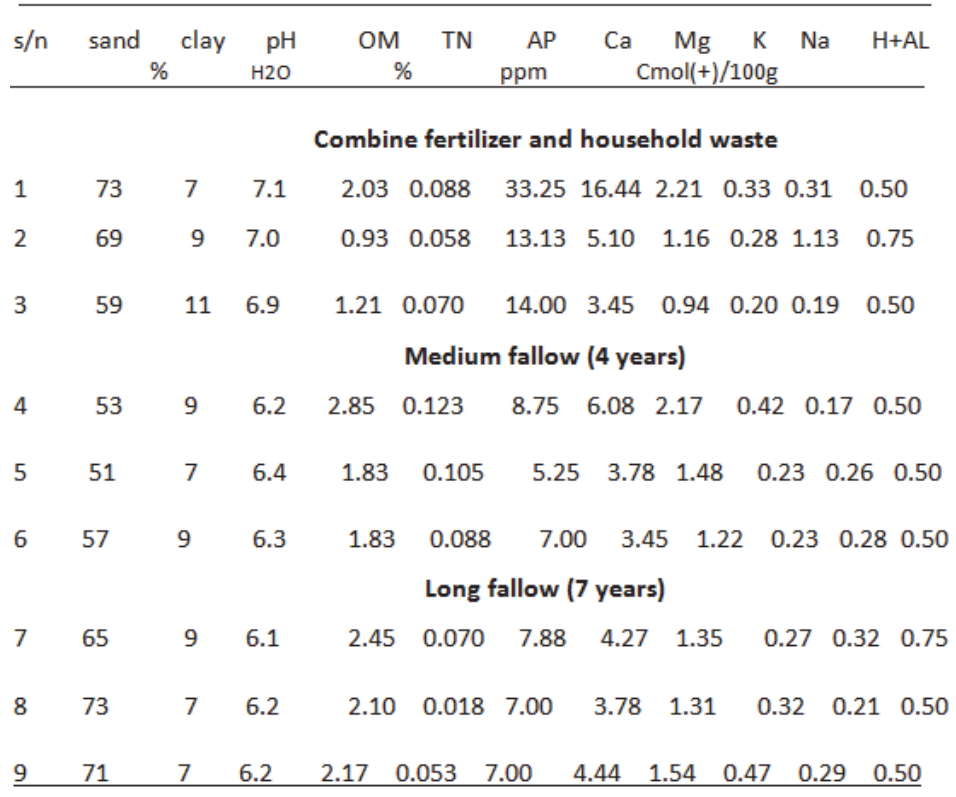

Source: Analyzed laboratory result (2010).

Table 2: Mean value of surface soil properties

\begin{tabular}{lccc}
\hline Soil properties & $\begin{array}{c}\text { combine fertilizer \& } \\
\text { Household waste }\end{array}$ & medium fallow & long fallow \\
\hline Clay $(\%)$ & 9.00 & 8.30 & 7.60 \\
Sand $(\%)$ & 67.00 & 53.67 & 69.67 \\
$\mathrm{pH}\left(\mathrm{H}_{2} \mathrm{O}\right)$ & 7.00 & 6.10 & 6.10 \\
$\mathrm{OM}(\%)$ & 1.39 & 1.91 & 2.27 \\
$\mathrm{TN}(\%)$ & 0.072 & 0.035 & 0.035 \\
$\mathrm{AP}(\mathrm{ppm})$ & 20.12 & 9.30 & 7.30 \\
$\mathrm{Ca}(\mathrm{Cmol}(+) / 100 \mathrm{~g})$ & 8.33 & 3.45 & 4.16 \\
$\mathrm{Mg}(\mathrm{Cmol}(+) / 100 \mathrm{~g})$ & 1.40 & 1.14 & 1.40 \\
$\mathrm{~K}(\mathrm{Cmol}(+) / 100 \mathrm{~g})$ & 0.27 & 0.29 & 0.30 \\
$\mathrm{Na}(\mathrm{Cmol}(+) / 100 \mathrm{~g})$ & 0.21 & 0.25 & 0.27 \\
$\mathrm{Total} \mathrm{bases}$ & 10.50 & 5.30 & 6.20 \\
Exch. Acidity $(\mathrm{H}+\mathrm{AL})$ & 0.50 & 0.75 & 0.60 \\
ECEC(Cmol $(+) / \mathrm{kg})$ & 11.16 & 4.60 & 6.60 \\
\hline
\end{tabular}

Source: Analyzed laboratory result (2010). 
Concerning exchangeable bases, there is no significant difference in exchangeable $\mathrm{Ca}, \mathrm{Mg}, \mathrm{K}$, and $\mathrm{Na}$ among the soils examined. Calcium and Magnesium being the most dominant cations both have the highest mean value in soil managed under combine fertilizer and household waste. The least value however occurs in medium fallow (table). The exception however occurs in $\mathrm{K}$ which has its highest mean value in long fallow. Lower levels of $\mathrm{Ca}$ and $\mathrm{Mg}$ in medium and long fallow may perhaps be caused by the decrease of clay content and TN in them.

Other negative properties such as $\mathrm{Na}^{+}$and exchangeable acidity (Yusuf, 2000) show no significant difference as well. Examination of the mean values of these properties (table 2) however has shown that, the magnitudes of the variables are lower in soil that is managed under combine fertilizer and household system. Higher content of exchangeable $\mathrm{Ca}, \mathrm{Mg}$ and $\mathrm{K}$ and the corresponding higher clay content in the soil may have resulted to the status. Olowolafe (2008) has made a similar observation. It has been observed by Yusuf (2000) that both exchangeable acidity and $\mathrm{Na}^{+}$constitutes negative properties whose increase indicates a decrease in fertility quality.

Similarly, both of the total bases and effective cation exchange capacity (ECEC) shows no significant difference, but the computed mean values of the variables have shown higher magnitude in soil managed under combine fertilizer and household waste, whereas lower magnitude occur in medium fallow managed soil. Various content and levels of clay and $\mathrm{pH}$ may have been resulted this status, since both of them have direct relationship particularly in tropical ferruginous soils (Olowolafe, 2008). The exchangeable bases such as $\mathrm{Ca}, \mathrm{Mg}$ and $\mathrm{K}$ are considered as positive properties (Yusuf, 2000), therefore their increase in magnitude is a clear indication of the corresponding increase in fertility quality

\section{Conclusion and Recommendation}

This study has shown that the fertility quality of the soil can be affected by the type of management systems practiced. The magnitude of positive soil properties such as clay, TN, AP, K, Ca, Mg, total bases and ECEC are both higher in soil that is managed under combine fertilizer and household waste. On the other hand the values of the negative properties such as sand, $\mathrm{Na}$ ions and exchangeable acidity were found to be higher in medium and long fallow respectively. This is clear indication that, the management of soil under combines usage of fertilizer and household waste stand best in replenishing the fertility quality of the soils and by extension the better and improved yield of the crops grown. Hence for sustained soil fertility retention and improved agricultural productivity, management of soil through combine fertilization and household waste application is recommended.

\section{References}

Bremmer, J.M and Mulvaney, C. S (1982). Nitrogen total. In A. L page R. H Miller and D. R Keeny (ed) method of soil analysis, part 2 chemical and microbiological properties $\left(2^{\text {nd }}-1159 p p\right)$.

Bauder, J. W. (1986). Particle size analysis. In : Klute A, editor method of soil analysis and mineralogical methods, Madison, WL American society of agronomy, 1986 pp $383-411$.

Diez, J.N (1982). Consideraciones sobre la utilizacion de la technical extractive de Fosforo asimilable en suelos. Anales de edapolagia,41(7-8): :1345-1353.

Faruk A. (2010). Impacts of fallow period on the soil chemical properties in Kafin Madaki area of Bauchi state. M.Sc. environmental and resources planning de Partment of Geography and planning, university of Jos, Nigeria.

Koppen, W. (1912). De klinmeteder erede berlin waterder gruiter.

Olowolafe, E. A (2008). Land use affects on the properties of alfisols on the Jos Plateau, Nigeria. Geojournal, 71, pp83-91.

USDA soil survey staff (1999). Soil taxonomy: a basic system of soil classification for making and interpreting soil survey. (2 ${ }^{\text {nd }}$ ed 86 90pp). agriculture hand book No. 436. Soil management support.

Yusuf, M. A (2000). Introducing soil fertility ranking model in some soils of semi arid north eastern Nigeria. Journal of social and management studies B.U.K Vol. pp 130 - 143.

Yusuf M. A. (1994). The influence of agricultural management on present and potential soil quality under small holder condition in Tumbau KCSZ. 